\title{
Euthanasia and the Newborn
}

R McMillan, H R Engelhardt, S
Spicker, editors, 313 pages,
Netherlands, £42.75, Kluwer
Academic Publishing Group, 1987

This thought-provoking book is a collection of essays from a symposium held in Georgia and it is worthwhile reading for anyone involved in the continuing debate regarding the treatment of handicapped babies, a topic which brings much anguish to parents and professionals alike and which is unlikely to be resolved by legislation. These essays set the controversy against an historical background of attitudes to the newborn, from the early Roman view that a child's value lies only in his potential (hence the ordeal of 'exposure of infants') through the early Christian view of the intrinsic value of the life of a child made in God's image, to the later Christian concept of animation of the fetus, to the current 'post-Christian' secular view that a child is ultimately a ward of the State. The usual controversy of when a fetus becomes 'a person' remains unsettled, suggestions varying from 40 days post-conception (males) to 90 days post-conception (females) to as late as $\mathbf{3 1}$ days after birth (orthodox Judaism), one author also suggesting that a mother does not 'bond' closely with her baby for the first few weeks of life. Legal and ethical views are aired in detail, with much emphasis on the concept of 'doing no harm', and the dilemmas as to whether by allowing a severely handicapped child to survive (or even to be born) one may be doing more harm than by offering euthanasia. This important dilemma is set against the current background of the ability of medicine to offer highly sophisticated treatment to increasingly immature newborns who may have actual or potential handicaps. With increasing technology must come responsible choice and the option not to treat or to withdraw treatment. But who is to decide, parents, doctors, a committee, or society?

Because the authors are all American, there is inevitably repeated consideration of the financial costs (in addition to the emotional costs) of treatment and survival - a factor which fortunately is not yet a major consideration in this country. But surprisingly little reference is made to the voluntary 'watchdog' groups, which have an increasing influence in this country.
Although there is a wealth of erudite discussion on the medical, legal, ethical, philosphical and religious aspects of the problem, with much humanity in all considerations, yet nowhere is the possibility entertained that a family might grow and develop from the tragedy of caring for a severely handicapped child - a consideration which would add $\mathbf{a}$ further dimension to the controversy. This is an unquantifiable possibility that should not be overlooked in the enthusiasm to define whether an individual life or death may be the greater good or evil.

Nevertheless, the reader of this book cannot fail to be inspired at least to examine his or her personal views, and the many issues discussed so widely and sensitively may indeed help the reader to reach decisions of his own, even if they do not coincide with the majority view implied by the authors. The issues raised by these essays need careful consideration from all those involved in care of the newborn.

DR J HAMMOND, Consultant Paediatrician Queen Mary's Hospital for Children, Carshalton, Surrey SM5 4NR

\section{The Price of Health}

George J Agich, Charles E Begley, 280 pages, Dordrecht, Holland, £39.50, Reidel, 1986

Contributors to this stimulating book are all from the USA and their arguments are directed at debates within the USA. But the issues explored are of concern to all countries.

The book is divided into four main parts: theoretical considerations of medical economics and ethics; philosophical views of costs and benefits in medicine; economics and ethics in health policy, and the role of providers in controlling costs and maximising profit. In addition to this structure a number of main questions run through the various papers, exploring the nature of rationing in health care. How has this been done in the past? What are the implications for the future, in particular, how may a 'decent minimum standard' of health care be defined? What is the nature of the argument about rationing? Is health care a right? What is the doctor's role given his commitment to individual patients? To what extent are rationing decisions amenable to conventional economic analysis? These questions are now familiar but their treatment here is almost invariably thoughtful. And where a main paper has failed to stimulate, it is followed by a challenging short paper which exposes and challenges assumptions that have been made too readily.

Of particular interest to this reader is the discussion of the role of economics in health-care rationing in the first two parts of the book. The care taken in the first part to establish the case that economics have an important role in decisions about health care probably reflects the USA's much shorter period of explicit cost-containment as compared with the UK. Roberts's examination of three philosophical bases of the application of economics to health care illustrates the gap between these and actual practice. But he argues against regarding health care as a right because this then suggests evasion of the rationing problem. As Agich emphasises, however, establishing that cost of health services is an ethically relevant consideration does not entail a free-market approach in which the price of health and health care is set solely as an exchange commodity. In the second part, Morreim discusses problems of measuring the quality of life in general, and the use of QALYs ${ }^{\star}$ in particular. She emphasises how they encounter the fundamental difficulty of interpersonal comparisons by illustrating the difference between subjective and objective standards of quality of life. And Wenz illustrates that the claimed superiority of cost-benefit and costeffectiveness analyses over intuitive decision-making is in essence a claim that the intuitive bases of those methods are superior, and this is not self-evident. He puts forward the US Supreme Court as a model of rational decision-making which does not rely on mathematical calculation and suggests that this alternative kind of reasoning is appropriate to deciding among competing goals and programmes when people's health is at issue.

Whatever discipline readers come from they will relish Begley's richly illustrated paper on physicians and costcontainment. This includes the example of Dr Harvey Cushing at Ypres who carefully operated on two patients a day when allied mortality was as much as 50,000 on some days not counting the wounded. And the tone of the book is set by Jonsen's erudite and entertaining foreword. I recommend this book to readers of this journal.

^ Quality Adjusted Life Years

GWYN BEVAN

Senior Lecturer in Health Economics Department of Community Medicine UMDS, St Thomas's Campus, London 